\title{
Stylistic devices in English legal concepts and their interpretation into Russian: metaphor in the focus
}

\author{
Olga Gorbatenko - Irina Kruse - Elena Kalashnikova
}

DOI: $10.18355 /$ XL.2019.12.04.07

\begin{abstract}
The article explores the language representation of specialized legal knowledge in English and problems of its interpretation by means of the Russian language. The relevance of the problem under study is due to the modern tasks of society with respect to conceptualization and interpretation of knowledge in various areas within a multilingual context. At the present stage of information processing, various pragmastylistic means are actively used for verbalization and structuring of legal knowledge. In this regard, the article aims at studying the process and tools for interpreting legal concepts that are formed with the use of metaphorical components. The study integrates theoretical approaches (linguistic-cognitive, pragmatic, sociocultural), methods of empirical analysis of linguistic-cognitive structures of knowledge production, and processing. The paper highlights the trends in the use of metaphors as an integral tool for representing legal English concepts. The article identifies the main types of metaphorical components that are used in the process of creating legal concepts, defines the tools and stages of their interpretation. Further, preliminary study is conducted with regard to challenges that translators and lawyers might face when providing interpretation of legal English concepts by means of the Russian Language. The materials of the article are of practical value for the training of lawyers who implement professional activities in bilingual environment and for translators who engage in legal translation.
\end{abstract}

Key words: language, linguistics, cognitive studies, frame modelling, specialized concepts, cross-language interpretation

\section{Introduction}

English operates as lingua franca in many fields of social activities. Law is no exception, being one of the fundamental forms of social consciousness and has a system of linguistic signs for the verbal presentation of cognitive activity outcomes in the corresponding specialized field. Therefore, Filmor's opinion seems to be logical with regard to statement that the legal language is of interest to specialists in the field of communication as an independent system (Filmor, 2006). Within the above context English legal concepts need adequate interpretation from the societal angle. This becomes even more important for cross-language communication in humanitarian contests, which require urgent and adequate interpretation (Atabekova, Belenkova, Shoustikova, 2018).

Academic studies traditionally note that the language functional and stylistic specifics in domain-specific scientific communication are revealed through lexical units (scientific concepts verbalized through terminological systems), semantic-syntactic organization of specialized texts, and their genre varieties. The terminology of the 21 st century is known to have established a solid tradition of analyzing terminological systems related to a specific area of science, production, etc. However, the postindustrial information society needs constant improvement of the knowledge processing, refinement of the ways of its conceptualization, and verbalization in the process of multilingual communication (Wagner, Sin, Cheng, 2016).

XLinguae, Volume 12, Issue 4, October 2019, ISSN 1337-8384, eISSN 2453-711X 
Within the above context, the theory of specialized concept as the cognitive-linguistic phenomenon that regulates specialized knowledge structuring (Atabekova, 2008) seems to be productive as it integrates the vision of cognitive processing of the objective reality data and its linguistics materialization through terms.

Currently, Academia considers the terminological nomination not only as a process of specialized concept identification but also as a process of cognition and presentation of its results (Faber, Reimerink, 2019).

In the above, subjective and objective understanding of reality are combined. The term is considered as a sign of a specialized concept that acts as a tool of cognition in the cognitive process, and that of fixation and transfer of scientific knowledge. Linguists insistently emphasize that it is necessary to move from the traditional standardization and definition of concepts to the study of terminological units in the text (Ahmad, 1993; Collet, 2004), in the context of communication (Pearson, 1998), within the corpus of legal terms (Pérez, 2016).

Moreover, the interdisciplinary approaches are on the research methodology agenda. Scholars promote a sociocognitive approach (Cabré, 2018; Temmerman, 2016), a linguocultural / sociocultural approach to the study of terminological systems (Corbeil, 1999; Diki-Kidiri, 2000; Humbley, 2018).

Specialists draw attention to the fact that a term is a unit of understanding and not just the linguistic equivalent of a concept. Many authors emphasize that the prototype theory by Helen Roche (Rosch, 1978) plays a significant role in interpreting units of specialized knowledge. Scholars underline that it is crucial to take into account the role of metaphorical categorization in the process of verbalization of knowledge, the objective fact of which contradicts the idea of a unique correspondence of sign and meaning in the process of formation and development of terms (Zawada, Swanepoel, 1994).

That is why researchers stress the need to study metaphor as a universal mechanism for verbalization of the cognitive practice of professional community members and draw attention to the fact that the ontology of human life is the most productive sphere of metaphorical understanding of special knowledge.

This aspect is even more important when the domain-specific academic communication takes place, and specific concepts of academic discourse or that of practitioners interaction are subject to actualization within cross-cultural and crosslanguage interaction.

Although, it should be stated that the study of metaphoric examples in various genres of legal discourse has been on the research agenda for a long time (Boldt, 2015; Castaño, Laso Martin, Verdaguer, 2017; Philippopoulos, Mihalopoulos, 2016). Nonetheless, the interpretation of conceptual legal knowledge through the use of metaphors has not become subject to study so far.

The above determines the present research timeliness and its scientific value.

The relevance of this study is determined by the general trends of the modern research paradigm, its interest in the problems of the interaction of language thought and culture in the course of interpreting specialized concepts of domain-specific knowledge.

The research novelty stems from the implementation of cognitive interpretative, linguistic, and cultural approaches to the analysis of metaphorization in the process of conceptualization, the verbal presentation of professionally oriented information, and its interpretation by means of another language in the field of communication on law issues.

The research hypothesis assumes that an adequate interpretation of the specialized legal concepts by means of another language requires an analysis of the pragmatic stylistic characteristics of the language units, ensuring their verbal presentation, and the interpretation procedure includes frame modeling of a special concept and verbalization of its constituent elements by means of another language. 
The research subject is the metaphorization of English legal concepts and their interpretation by means of the Russian language.

The object of analysis is the cross-language interpretation procedure with regard to legal English concepts and their verbalization in Russian.

The goal of this study is to analyze the process and identify means for interpretation into Russian of legal English concepts, created on the basis of metaphors.

This goal is achieved by solving the following tasks:

- define theoretical approaches to the study of the process of interpreting legal knowledge in the context of intercultural professionally-oriented communication, mediated by a metaphorical perception and verbalization of reality;

- explore the trends in the use of metaphors as an integral tool for representing legal English concepts;

- identify the tools and stages of the process of frame modeling of a legal English concept with the correlations of another language in the conditions of an interlanguage interpretation of specialized concepts created through the use of metaphor;

- conduct a preliminary study of challenges that translators and lawyers might face when providing interpretation of legal English concepts by means of the Russian Language.

\section{Literature Review}

The modern paradigm of humanitarian knowledge is characterized by a pronounced ethno / sociocultural emphasis. Culture determines the mentality of society as a whole. According to anthropologists, its differential features are concepts, relations, values, rules (Ferraro, 1995; Samovar, Porter, 1995).

In the last two decades, subcultures that are formed on a professional or corporate basis have drawn an increasing interest of researchers.

A professional subculture is understood as a complex of concepts, traditions, stereotypes of behavior, genres of institutional discourse, symbolism, and attributes that have been developed in the respective professional environment (Hofstede, 1991). In this context, legal culture is seen as one of the subcultures of society that correlates with the corresponding form of public consciousness. Law is interpreted as a factor in the socio-normative sphere of national culture (Hibbitts, 1996). Accordingly, subcultures of a particular society form a layer of special knowledge, ideas about traditions typical for them, and norms of behavior.

That is why the process of working with legal texts in a foreign language often requires the interpretation of a foreign language concept, the search for a functional analog (which is not always equivalent), the use of such translation techniques as description and commentary (Garzone, 1999; Sarcevic, 1989).

Therefore, to study the procedures of legal concepts cross-language interpretation, a cognitive approach is important.

Throughout the 20th and beginning of the 21 st centuries, linguists use various terms to refer to these structures: schemes (Bartlett, 1932), scenarios (Shank, Abelson, 1977), frames (Green, 1974; Minsky, 1975), models / structures (van Dijk, 1985).

Since the concept is multidimensional, the frame, script, script, having a clearer structure, can be used to model the concept for its further interpretation in another language (Atabekova, 2016).

A-frame structures diverse information. In this regard, it is critical to bear in mind that the mental vocabulary is represented by objective connotations, pragmatic components that form (in addition to the existing encyclopedic and linguistic) complex knowledge (Troschina, 1995). 
In the context of the growing differentiation and stratification of the branches of specialized professional interaction between members of society, it is natural to consider issues related to the pragmatic features of language tools in the verbal presentation of special knowledge.

Moreover, studies of English legal discourse suggest that pragmastylistic figurative meanings are an integral component in the semantics of cognitive-information models that are verbally represented by legal terms (Tiersma, 1999). This situation seems logical.

The ability to produce figurative meanings is the oldest cognitive operation of human consciousness, an integral part of the ontology of cognitive processes.

Metaphor and metonymy are considered in linguistics as two basic models of human experience structuring (Lakoff, Johnson, 2008). The metaphor is studied from various angles. It is the subject of study of various sciences. For the purposes of this study, it is important that in semantic research a metaphor is considered as one of the means of secondary nomination by using the word in figurative meaning. This approach is the basis for studies of the essence and potential of metaphor from the standpoint of cognitive linguistics.

In addition, for an interlanguage interpretation, it is necessary to take into account that in the aspect of the theory and practice of translation, dead (perceived as a direct naming) metaphors, cliché metaphors, standard metaphors, only metaphors that appear in the language and original author's metaphors (dead, cliché, standard) are considered, adapted, original metaphors (Newmark, 2000).

The above-mentioned data confirms the importance of research on metaphor as a tool for specialized knowledge representation and its interpretation.

\section{Methodology}

The study was carried out within the framework of the qualitative paradigm. The analysis integrated theoretical analysis and empirical studies.

The investigation of the literature on the theme under study aimed at building the research theoretical background. The empirical analysis strived to explore the procedure of the legal concept frame modeling by means of another language.

The empirical study moved from the analysis of the linguistic form of the English legal concept to the analysis of its meaning. Further, the identification of the constituent semantic elements of the corresponding legal concept took place. Next, search for their equivalents in the Russian language was implemented, and finally, the verbal representation of the English legal concept by means of the Russian language was explored.

Materials for empirical analysis were taken from academic textbooks on various branches of law, designed for non-native English speakers.

The materials included more than 2,000 language units with stylistic devices that verbalized special concepts in various branches of Anglo-Saxon law.

These units were structured into legal concepts corpus. It was subject to empirical studies aimed to identify metaphorical tools for legal knowledge conceptualization. It should be noted that metaphors that have fixed equivalents across languages were outside the research material scope. Such language units have a set equivalent in the bilingual dictionary, though they might be rendered into the Russian language not only through the calque (for instance, the laws sаys/закон гласит), but also through the reformulation (to be caught red-handed / быть пойманным с поличным, на месте преступления), or semantic modulation (the body of the court/cocmaв суда).

The research focused on the metaphoric conceptualization of legal realities that mostly (but not always) might be subject to the explanation in monolingual encyclopedias and reference books. 
In the course of study, we did not limit the selection of language material to anyone's legal branch and aimed to trace some general trends in the interpretation of English legal concepts by means of the Russian language.

The study also used data from legal encyclopedias, monolingual and bilingual dictionaries of the British and American versions of the Legal English language, as well as phraseological dictionaries and reference books.

The research used a set of techniques. First, general scientific methods were used: a descriptive method, including observation techniques and generalizations of the analyzed material, induction, and deduction.

Next, a number of methods were applied in the search for interpretation tools, including methods of structural linguistics (component, opposite and distributive), cognitive and procedural linguistics (conceptual frame analysis), cultural and contextual analysis.

An experiment on the interpretation of English-language legal concepts by means of the Russian language also took place with the participation of two focus groups.

Based on empirical analysis, a list of 100 legal English concepts that are not included in standard bilingual English-Russian legal dictionaries was proposed for interpretation into Russian to members of two focus groups. The first one included 20 professional translators with more than 5 years of experience, but with-out specialization in legal translation. The second group included 20 lawyers who mastered English at B2 level.

Focus group members were invited to interpret the above concepts using the Russian language, with the possible use of dictionaries and encyclopedias, and then provide answers to the open-ended questionnaire with regard to challenges they faced in the course of cross-language interpretation.

The questions were the following:

- Did you face any challenges in the course of cross-language interpretation of Legal English concepts? Yes/No

- What challenges did you face?

- What were the possible reasons for the mentioned challenges?

\section{Results and Discussion}

The results of the analysis indicate that over $30 \%$ of linguistic resources in the design of legal concepts used stylistic devices. Within the indicated volume, the maximum value belongs to metaphor and metonymy, followed by evaluative epithets and anthroponymic concepts. See figure 1 . 


\section{Pragmastylistic devices}

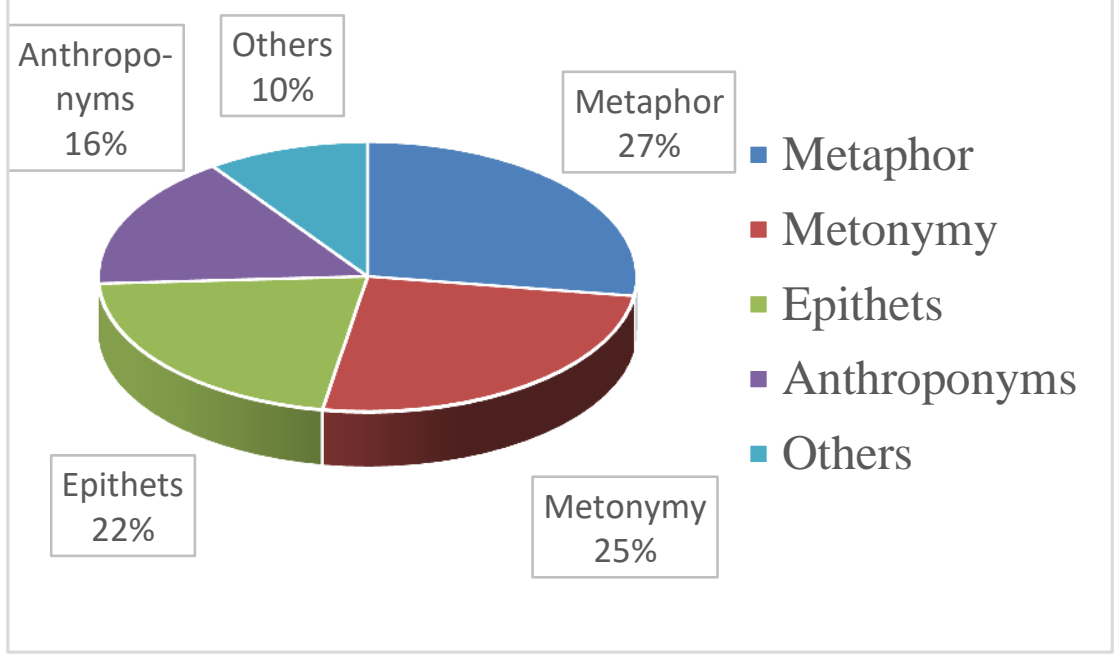

Figure 1. Pragmastylistic devices in Legal English concepts (Authors' data)

As the data shows, various types of metaphor perform the maximum load. Among the metaphor domain, there were identified anthropomorphisms, zoonyms (animalisms), color metaphors with a metonymic component inclusion. Let us consider examples and findings.

\section{Anthropomorphisms in the verbal representation of legal concepts.}

In the process of communication, inanimate subjects, living creatures, and fictional entities that are different from humans in nature have long been credited with the physical and mental qualities of humans. Such objects were endowed with the ability to experience various feelings and carry out meaningful human actions. This phenomenon is a metaphorical transfer qualified as anthropomorphism that includes the use of somatisms (words naming the human body), terms of family relations, etc. The results of our study indicate that anthropomorphism as a way of language nomination is used in the verbalization of special concepts in the field of law.

The study of legal texts suggests that in this variety of professional discourse, the paradigm of designing special concepts is created by stable combinations with the somatic components (head, back, body, , foot, etc.) and family relations (father of the bar, ship's husband) which actualize their figurative meanings, for example: back-toback agreement, arm of court, etc.

The experiment to assess the degree of adequacy of the interpretation of foreign concepts showed that non-native speakers understand the essence of a foreign language concept (82\% of informants) due to their legal domain professional knowledge. However, may experience difficulties with the selection of semantically adequate linguistic units be regularly used in the context of a "native" professional culture (38\%), which is explained by the lack of direct bilingual metaphors within foreign and domestic legal cultures, and legal languages, respectively.

In this situation, the frame modeling of the structure of a foreign language concept seems efficient. The process includes the frame constituent slots identification, their respective language units' analysis, search for semantic equivalents by means of 
another language, selection of another language forms to adapt the legal concept interpretation to the system of the target language.

The slots identification can be seen below in the course of the cross-language interpretation into Russian of the English legal concept head-note.

Figure 2. Slots in the frame of concept "head-note" (Authors' data compiled from monolingual English sources)

\section{Head-note}

- summary of

- a particular point of law

- brief document

- added to the text of

- court decision

- to aid readers

- in interpreting the highlights of an opinion.

- appear at the beginning of the published opinion.

The identification of these slots allows interpreting the English concept using the Russian language: краткое изложение основных вопросов по решенному делу перед полным изложением последнего в сборнике судебных решений.

Anthropomorphism was the dominant principle of reality cognition in the early stages of civilization development. Experts attribute this fact to the fact that the anthropomorphic components represent the most accessible and studied object of observation from the first days of the individual's existence, to navigate in space, to evaluate phenomena of reality is "more convenient" for a person in relation to his/her body, terms of family relations, etc. (Johnson, 1998).

Somatisms are one of the oldest layers of the vocabulary of any language. Specialists note that they are able to form a complex system of figurative meanings and have increased productivity in the field of education of phraseological units (Zubillaga, Sanz, Uribarri, 2015).

As for the present research findings, it can be noted that in the verbal representation of legal concepts, the phenomenon of anthropomorphism operates regularly. In terms of parts of speech, names (nouns and adjectives) are widely used.

As a general trend, anthropomorphism in the process of legal concepts verbalization increases the emphasis on the peculiarities of the legal situation, on the belonging to a certain corporate community, or on exclusion from it.

The process of including anthropomorphic metaphors in the characterization of a person's socio-professional status cannot be clearly systematized, which can cause cognitive dissonance and an erroneous interpretation of the foreign concept.

\section{Zoonyms in the verbal representation of legal concepts}

Animalist components reflect the characteristics of a person's cognitive activity in relation to extralinguistic reality. Therefore, researchers consider the phenomenon of zoometaphor (Bukovčan, 2016).

The results of our analysis suggest that in the process of language nomination of legal concepts, the most common are language units that convey specific personality and social-role characteristics of the subject in an assessing way.

Moreover, our research materials dominate those terms, in which the features of animals more often acquire negative semes $(67 \%)$ when transferred to humans, indicating negative personality characteristics in connection with professional activities, which are reinforced by the use of zoonyms as a metaphor. However, as in the case of somatisms and kinship metaphors, in the process of interpreting, the metaphor is neutralized by accepting the description of all significant slots in the frame structure of the English-language concept. 
Figure 3. Slots in the frame of concept "loan shark" (Authors' data compiled from monolingual English sources)

\section{Loan shark}

- a person

- financed and supported

- by

- an organized crime network

- lends money

- at exorbitant interest rates

The interpretation into Russian can be as follows:

Loan shark - человек, дающий в долг под очень высокие проценты.

Animalisms can also be used to characterize legal procedure specificity.

Let's consider a combination leapfrog procedure.

Figure 4. Slots in the frame of concept "leapfrog procedure" (Authors' data compiled from monolingual English sources)

\section{Leapfrog Procedure}

- UK Law

- Appeals

- taken from the High Court direct to the House of Lords

- (ss12-15 Administration of Justice Act 1969).

- conditions which must be satisfied before such a direct appeal can be taken are that:

(a) the trial judge has granted a certificate of satisfaction, (b) the House of Lords has given leave to appeal.

(c) a trial judge can only grant a certificate if all the parties consent and the case involves a point of law of general public importance which is either concerned wholly or mainly with the construction of a statute or of a statutory instrument, or is one where the trial judge is bound by a previous decision of the Court of Appeal or the House of Lords. The granting of a certificate by the trial judge is discretionary. No appeal is possible against the granting or refusal of a certificate.

The following slots can be used for interpretation of this concept: slots denoting the national framework of the procedure (UK Law), actors of the situation (High Court, the House of Lords), operational variables (conditions a, b, c), scenario presentation of the procedure (taken from the High Court direct to the House of Lords).

The identification of the above slots and search for equivalents in Russian leads to the following interpretation of the legal English concept:

The Leapfrog Procedure - по английскому общему праву, процедура подачи апелляции непосредственно в палату Лордов, минуя Апелляиионный Суд, при соблюдении ряда условий...

The present results confirm through the new empirical materials and a new domain specific knowledge that zoonyms can perform various functions in communication, characterizing anthropocentric aspects (qualities of a person's character, his actions, state, realizing an invective function (Hawhee, 2017).

In the legal communication zoonyms can evaluate professional qualification, belonging to some legal professional activities, legal procedure, legal situation from the angle of law and order.

\section{Color names in legal concepts: integrating metaphor and metonymy}

The results of our analysis indicate that in the course of knowledge processing in the legal sphere and the verbal presentation of its results, color names play a serious role. It should be noted that the laws of verbalization of color perceptions have long been subject to studies within various fields of science. At the end of the 1960s, B. Berlin and P Kay (Berlin, Kay, 1969) considered basic universal color names that were used by representatives of different linguistic cultures and identified universal colors 
used in the processes of perception and cognition by speakers different languages (red, yellow, green, blue, brown, pink, orange, black, white, gray and magenta).

The processes of cognitive processing of reality through colors remain in the focus of linguistic-cognitive analysis for a considerable period of time (Heider, 1972; Casson, Gardner, 1992; Hardin, Maffi, 1997; Thierry et al., 2009). The results of our analysis indicate that the conceptualization of the realities related to knowledge and communication in the legal sphere uses basic universal colors.

It should be noted that English-language professional communication in the field related to the discussion of legal and legislative aspects selectively refers to color. The most commonly used colors are blue, black, yellow, red, white, gray, green.

Blue and green colors realize mostly positive (permissive) components. Let's consider a number of examples, see Figures 5 and 6.

Figure 5. Slots in the frame of concept "Blue sky law" (Authors' data compiled from monolingual English sources)

\section{Blue sky law (Am.E.)}

- An American law term

- that refers to

- government controls,

- through statutes,

- of the sale of securities

- to the public.

The search for Russian equivalents of these slots results in a number of language units that will be arranged in the following utterance: Закон, регулирующий выпуск $и$ разрешающий продажу акций и иенных бумаг.

Figure 6. Slots in the frame of concept "green card"

\section{Green card (Br.E.)}

- The Green Card

- or International Motor Insurance Certificate

- is equivalent

- to the national motor insurance certificates

- of all of the countries a motorist visits.

The search for Russian equivalents of these slots results in a number of language units that will be arranged in the following interpretation:

Страховой полис «Зеленая карта» является обязательным полисом страхования гражданской ответственности владельцев транспортных средств, на территории стран - участнии данной системы.

It is interesting to mention that the black color can bear both positive and negative assessments. Two examples show two opposing situations.

Black color is often a marker of negative phenomena, including the linguistic representation of legal concepts. A similar example and its interpretation by means of the Russian language follows, see Figure 7:

Figure 7. Slots in the frame of concept "black list" (Authors' data compiled from monolingual English sources)

\section{Black list}

- a list of people or things

- that are regarded as

- untrustworthy

- and should be excluded or avoided.

As a contextual option in administrative-legal communication, one can come across the following interpretation: black list - (черный список) список несостоятельных должников. 
The following example shows the positive potential of the black color name in the legal concept verbal representation, see Figure 8.

Figure 8. Slots in the frame of concept "Black Letter Law" (Authors' data compiled from monolingual English sources)

\section{Black Letter Law (Am.E)}

- the basic standard elements or principles of law,

- which are generally known

- and free from doubt or dispute.

- the basic principles of law

- that are accepted by a majority of judges in most states.

- well-established case law.

The search for Russian equivalents of these slots leads to the language units that will be organized in the following explanation:

Закон “черной буквы”" (относится к основным стандартным элементам или принципам права, которые общеизвестны и не подлежат сомнениям или спорам). Он описывает основные принципы права, которые принимаются большинством судей в большинстве штатов. В американской правовой системе это также означает хорошо устоявшееся прецедентное право.

And the possible footnote might include the following commentary:

Название связано с традицией составления книг по праву и цитирование правовых прецедентов в виде «черного» шрифта, эта традиция сохранялась еще долго после перехода на римский и курсивный текст для других печатных работ.

The analysis allows for the following summary.

The metaphors of kinship, somatisms, animalisms, constructions, including color identification, function in legal discourse as professionally marked precedent texts, are keywords of national legal culture.

The findings allow us to say that concepts with metaphorical units reinforce the pragmatics of legal discourse, reveal a linguocultural component in domain-specific field of knowledge, and represent the cognitive-linguistics level of the person who performs cross-language interpretation. The present empirical research based on the new material confirms that it is critical to take it into account when dealing with figurative components in cross-language mediation in administrative-legal settings (Atabekova, Shousikova, 2018).

The use of metaphors in the legal English concepts is objectively possible due to a number of reasons, namely the following:

- in connection with the metonymic and metaphorical transference as ways of mastering extra-linguistic reality;

- in connection with the traditions of perception of extra-linguistic reality within the respective society;

- in connection with the actualization of the pragmatic component of the term meaning, which provides the axiological orientation of the respective professional community.

Verbalization of professional culture concepts with metaphorical elements reflects specific traditions of a particular corporate community, the social (professional) status of the subject, indicates a legal evaluation of actions from the legal point of view. Interpretation of legal concepts, including color names, animalisms, in some cases may include calques, followed by commentary or explanation. The noted trends in the use of metaphorical components in the verbal representation of legal English concepts should be taken into account in the process of their interpretation by means of another language.

The empirical analysis showed that the interpretation of the concepts neutralizes the metaphorical component in the frame structure. The most important meaningful slots 
turn to be those that characterize the subject situation, its actors, the direction of their interaction, the operational variables indicating their national, professional, social characteristics are relevant. That is why, in the process of interpreting legal English concepts, which include metaphorical units, they are neutralized by a detailed description of the concept in accordance with the slots that organize its frame.

\section{Survey of translators and lawyers}

As it was mentioned earlier, a list of 100 legal English concepts that are not included in standard bilingual English-Russian legal dictionaries was proposed for interpretation into Russian to members of two focus groups that included professional translators and lawyers, respectively.

As far as the interpretation procedure was concerned, lawyers made $10 \%$ of syntactical mistakes with no factual errors. Translators were less successful as, on average, $9 \%$ of interpretation samples contained factual errors.

The analysis of errors has revealed that the causes of errors in the understanding and use by foreigners of terminological combinations in which the metaphoric phenomenon is included are due to the perception of the corresponding units not as a holistic, stable formation, but as a free phrase.

Regarding the questionnaire, the following data were obtained.

All the translators mentioned challenges related to the sense of the legal English concept that was often unclear and vague, even when the explanation was found in the reference source.

The reason for this situation they viewed in the lack of procedural and material legal knowledge. They also mentioned the difficulties with the selection of the right language words in Russian. They explained this problem was due to the synonymy and polysemy as language universals. Meanwhile, legal interpretation strives to precise and context-specific definition.

As for lawyers, they did not mention challenges related to the sense of legal English concepts as their professional background helped them. However, the legal practitioners noted as challenging the lack of information on the specific national legal culture affiliation of the legal concepts under study. Moreover, lawyers also referred to the specifics of Russian language syntax as compared to the English syntax. The differences led to challenges in interpretation regarding the coordination of the sentences, phrases, parts of the complex syntactical structures.

A survey of informants confirms that specialists working in an intercultural legal environment should have the skills of conceptual, component (semantic) analysis, frame modeling of the content of special foreign language concepts (Atabekova, 2011) that might include metaphoric components.

The specified stages of identifying the slots of such a special concept frame, and the tools for their interpretation by means of another language, contribute to improving the quality of interlanguage legal interpretation, due to the detailed processing of information components (Atabekova, Gorbatenko, 2017).

\section{Conclusion}

The study confirmed the research hypothesis and revealed that assumes that an adequate interpretation of the specialized legal concepts by means of another language requires an analysis of the pragmatic stylistic characteristics of the language units. The analysis also proved the relevance of frame modeling of a legal concept for quality interpretation.

A-frame as a prototypical structure seems to be the optimal starting point for the interpretation of a legal concept represented in a foreign language. In this process, one can distinguish a number of stages of its modeling by means of another semiotic language system. At the stage of perceiving a foreign-language concept, its content is identified, frame slots are singled out, correspondences are found between the

XLinguae, Volume 12, Issue 4, October 2019, ISSN 1337-8384, eISSN 2453-711X 
knowledge components structured into the frame of the interpreted concept, and the conceptual apparatus of the interpreter.

At the interpretation stage, the frame of the interpreted concept is mentally created within the framework of a semiotic foreign system. Prototypical correspondences of knowledge are singled out, based on this, slots are determined that are correlated with each other in the frame structure of foreign and interpreted concepts. Based on the correspondence of the slots, a frame is structured, the framework of which limits the circle or set of verbal and non-verbal elements necessary for the subject to interpret knowledge by means of another (native) language. The allocation of frame slots is determined by the context. Therefore, it seems possible to talk about the dynamic nature of the resulting frame interpretation. At the final stage, the linguistic presentation of the results of the individual's cognitive and interpretative practice on the linguistic design of the created frame takes into account the semantic-syntactic features of the linguistic form, which forms the corresponding foreign concept in the "native" professional culture. Therefore, a comparative cross-language analysis of frame slots is effective for searching conceptual equivalents, since it allows the specialist to clearly structure the information contained in the text, determine the data verbalizing conceptual reality and the information gap zones.

The results of the analysis indicate that frame modeling of the concept structure allows specialists to identify pragmatic resources of its linguistic form in relation to its functioning in a special branch of knowledge. In our opinion, the results of the analysis are important for intercultural communication. It is necessary to systematize the knowledge of legal specialists about possible metaphorical ways of reflecting legal concept constituent units in the cross-language knowledge processing and conceptualization.

Skills of interpreting legal concepts across languages are components of not only the communicative foreign language competence itself. These skills contribute to the development of systemic and specific professional competencies.

The results of the analysis can be used to further study of the means and methods of verbal representation and processing specialized knowledge in the field of information theory and in interdisciplinary research of scientific communication. The data obtained can be included in courses of language for specific purposes, theory, and practice of legal translation, practical courses on the style of English.

\section{Acknowledgments}

The publication has been prepared with the support of the RUDN University 5-100 project.

\section{Bibliographic references}

AHMAD, K. 1993. Terminology and KnowledgeA acquisition: A Text-Based Approach, TKE. Frankfurt: Indeks Verlag. ISBN: 9783932004254

ATABEKOVA, A. - BELENKOVA, R.N. - SHOUSTIKOVA, T. 2018. Language Management in Humanitarian Contexts: Unscheduled Migration. In: European Research Studies Journal, vol. 3, pp. 659-674. ISSN: 1108-2976.

ATABEKOVA, A. - SHOUSTIKOVA, T. 2018. Language Issues within Forced Migration at Borders and Temporary Settlements: An Integrated Content Analysis. In: European Research Studies Journal, vol. 21, pp. 690-700.

ATABEKOVA, A. - GORBATENKO, R. 2017. Multilingual Community and Translation: Focus on Information Processing to Enhance Quality. International Information Institute (Tokyo). In: Information, vol. 20, no. 7A, pp. 4677-4691. ISSN 1343-4500.

ATABEKOVA, A. 2016. Visualization in Legal Translation: a Tool for Knowledge Representation and Interpretation, INTED 2016 Proceedings, vol. 1, pp. 4942-4946. ISBN: 978-84-608-5617-7 ISSN: 2340-1079. 
ATABEKOVA, A. 2011. Insights into Multilingual Training Methodology for Lawyers-to-be: Challenges and Solutions. In: EDULEARN11 Proceedings, pp. 49794982. ISBN: 978-84-09-12031-4

ATABEKOVA, A. 2008. Foreign-language special concepts in intercultural professionally oriented communication. Moscow: RUDN.

BARTLETT, F. 1932. Remembering. Cambridge: Cambridge University. ISBN-10: 0521483565 .

BERLIN, B. - KAY, P. 1969. Basic Color Terms: Their Universality and Evolution. Berkeley: University of California Press. ISBN-10: 1575861623

BOLDT, J. 2015. Synthetic biology: Metaphors, worldviews, ethics, and law. London: Springer. ISBN 9783658109882

BUKOVČAN, D. 2016. A contrastive analysis of metaphors and phrasemes in LSP. In: Fluminensia: časopis za filološka istraživanja, vol. 28, no. 1, pp. 143-162. ISSN 0353-4642

CABRÉ, M.T. 2018. De la diversidad a la variación en la Teoría Comunicativa de la Terminología. In Terminoloxía: a necesidade da colaboración. Spain: Iberoamericana. ISBN: 978-84-16922-87-1

CASSON, R.W. - GARDNER, P.M. 1992. On brightness and color categories: Additional data. In: Current Anthropology, vol. 33, no. 4, pp. 395-399. ISSN: 00113204.

CASTAÑO CASTAÑO, E. - LASO MARTIN, N.J. - VERDAGUER, I. 2017. Immigration metaphors in a corpus of legal English: an exploratory study of EAL learners' metaphorical production and awareness. In: Quaderns de Filologia. Estudis Lingüístics, vol. 22, pp. 245-272. ISSN 1135-416X.

COLLET, T. 2004. What is a term? In: Temmerman R. \& Knops U. (Eds.) The Translation of Domain-Specific Languages and Multilingual Terminology Management. In: Special issue of Linguistica Antverpiensia, pp. 99-112. ISSN: 22955739 .

CORBEIL, J.C. 1999. La plurilinguisme terminologique. Terminología y modelos culturales. Institut universitari de lingüística aplicada (IULA). Barcelona: Universitat Pompeu Fabra. ISBN: 84-477-0667-2.

DIKI-KIDIRI, M. 2000. Une approche culturelle de la terminologie. Terminologies nouvelles. In: Terminologie et diversité culturelle, vol. 21, pp. 27-31. ISSN: 10155716

FABER, P., - REIMERINK, A. 2019. Framing terminology in legal translation. In: International Journal of Legal Discourse, vol. 4, n. 1, pp. 15-46. ISSN 2364-883X.

FERRARO, G. 1995.Cultural Anthropology. USA, West Publishing Company. ISBN10: 0495100102.

Fillmore, C. J. (2006). Frame semantics. Cognitive linguistics: Basic readings, 34, 373-400. ISBN 978-3-11-019990-1.

GARZONE, G. 1999. The Translation of Legal Texts. A Functional Approach in a pragmatic Perspective. In: TEXTUS (translation Studies Revisited), vol. 12, pp. 393 409. Italy, Genoa. ISSN: 1824-3967.

GREEN, G. 1974. Semantics and syntactic regularity. London: Bloomington. ISBN 10: 025335160X.

HARDIN, C. - MAFFI, L. 1997. Color Categories in Thought and Language. Cambridge: Cambridge University Press. ISBN-10: 0521498007.

HAWHEE, D. 2017. Rhetoric in Tooth and Claw: Animals, Language, Sensation. Chicago: University of Chicago Press. ISBN 9780226398174.

HEIDER, E. 1972. Universals in color naming and memory. In: Journal of Experimental Psychology, vol. 93, n. 1, pp. 10-20. ISSN: 0096-3445.

XLinguae, Volume 12, Issue 4, October 2019, ISSN 1337-8384, eISSN 2453-711X 
HIBBITTS, B.J. 1996. Senses of Difference: A Sociology of Metaphor in American Legal Discourse. Lionel Bentley \& Leo Flynn (Eds). Laws of the Senses. London: Pluto Press. ISBN-10: 0745310680.

HOFSTEDE, G. 1991.Cultures and organizations: software of the mind. New York: McGraw-Hill. ISBN-10: 0071664181.

HUMBLEY, J. 2018. Socioterminology. In: Languages for Special Purposes: An International Handbook, vol. 1, pp. 423-469. ISBN 978-3-11-022801-4.

JOHNSON, B. 1998. Anthropomorphism in Lyric and Law. In: Yale Journal of Law and Humanities, vol. 10, pp. 511-549. ISSN: 1041-6374.

LAKOFF, G. - JOHNSON, M. 2008. Metaphors we live by. Chicago: University of Chicago Press. ISBN: 9780226470993.

MINSKY, M.A. 1975. Framework for Representing Knowledge.in Winston P.H. (Eds.) The Psychology of Computer Vision. New York: Routledge. ISBN-10: 0070710481.

NEWMARK P. 2000. A textbook of translation. London: Routledge. ISBN 0-13912593-0.

PEARSON, J. 1998. Terms in Context. Amsterdam: John Benjamens. ISBN 9789027222695.

PÉREZ, M.J.M. 2016. Measuring the degree of specialisation of sub-technical legal terms through corpus comparison. Terminology. In: International Journal of Theoretical and Applied Issues in Specialized Communication, vol. 22, n. 1, pp. 80102. ISSN 0929-9971.

PHILIPPOPOULOS - MIHALOPOULOS, A. 2016. Flesh of the law: material legal metaphors. In: Journal of Law and Society, vol. 43, n. 1, pp. 45-65. ISSN: 1467-6478.

ROSCH, E. 1978. Principles of Categorization. Cognition and Categorization. Oxford: Lawrence Erlbaum. ISBN-10: 0470263776.

SAMOVAR, L.A. - PORTER, R.E. 1995.Commnication between Cultures. 2nd ed. Wadsworth: Wadsworth Publishing Company. ISBN-10: 111134910X.

SARCEVIC, S. 1989. Conceptual Dictionaries for Translation in the Field of Law. International Journal of Lexicography, vol. 2, no. 4, pp. 277-293. ISSN 0950-3846.

SHANK, R.C. - ABELSON, R.P. 1977. Scripts, Plans, Goals and Understanding: An Inquiry into Human Knowledge Structure. New York: Hillsdate. ISBN-10: 0898591384.

TEMMERMAN, R. 2016. Translation and the dynamics of understanding words and terms in contexts. Cambridge: Cambridge Scholars Publishing. ISSN - 1-4438-87048.

TIERSMA, P. 1999. Legal Language. Chicago: University of Chicago Press. ISBN10: 0226803031 .

THIERRY, G. - ATHANASOPOULOS, P. - WIGGETT, A. - DERING, B. KUIPERS, J.R. 2009. Unconscious effects of language-specific terminology on preattentive color perception. In: Proceedings of the National Academy of Sciences of the United States of America, vol. 106, no. 11, pp. 4567-4570. DOI:10.1073/pnas.0811155106

TROSCHINA, N. 1995. Kommunikativen Kontext und stilistische Frames. In: Wodak, R. and Kirsch, P. (Eds). Totalitäre Sprachen- Langue de bois - Language of dictatorship. Wien: Passagen Verlag. ISSN 1028-3625 25.

VAN DIJK, T.A. 1985. Cognitive Situation Models in Discourse Production. Language and Social Structure. New York: Springer Verlag. Online ISBN 978-14612-5074-6.

WAGNER, A. - SIN, K.K. - CHENG, L. 2016. Cultural transfer and conceptualization in legal discourse. In The Ashgate Handbook of Legal Translation. London: Routledge. ISBN-10: 1409469662 
ZUBILLAGA, N. - SANZ, Z. - URIBARRI, I. 2015. Building a trilingual parallel corpus to analyse literary translations from German into Basque. In: New directions in corpus-based translation studies, vol. 1, pp. 71-92. ISBN-10: 3944675754

Words: 6708

Characters: 46351 (25,75 standard pages)

Associate Professor Olga Gorbatenko, PhD.

Department of Foreign Languages, Law Institute

Peoples' Friendship University of Russia-RUDN University

6 st. Miklukho-Maklaya,

117198 Moscow

Russia

Gorbatenko-og@pfur.ru

Associate professor Irina Kruse, $\mathrm{PhD}$.

Department of Foreign Languages, Law Institute

Peoples' Friendship University of Russia-RUDN University

6 st. Miklukho-Maklaya,

117198 Moscow

Russia

Kruse-ii@pfur.ru

Elena Kalashnikova, Senior teacher

Department of Foreign Languages, Law Institute

Peoples' Friendship University of Russia-RUDN University

6 st. Miklukho-Maklaya,

117198 Moscow

Russia

Kalashnikova-ep@pfur.ru 